\title{
Economic Analysis of Transforaminal Lumbar Interbody Fusion Surgery Utilizing a Curved Bone Removal Device
}

\author{
John H. Peloza ${ }^{1} \cdot$ Michael A. Millgram² ${ }^{2}$ - Erel Jacobian ${ }^{2} \cdot$ Daniel E. Kolsky $^{2} \cdot$ Richard D. Guyer $^{3}$. \\ Jean-Charles Le Huec ${ }^{4}$. Ely Ashkenazi ${ }^{2}$
}

Accepted: 31 December 2020 / Published online: 19 January 2021

(c) The Author(s) 2021

\begin{abstract}
Background Transforaminal lumbar interbody fusion (TLIF) represents a commonly performed spinal procedure that poses a significant financial burden on patients, hospitals and insurers. Reducing these costs, while maintaining efficacy, may be assisted by a new powered endplate preparation device, designed to shorten procedural time while offering positive impacts on other elements that contribute to the cost of care.

Objective The aim of the study was to assess and compare the individual cost elements of TLIF procedures with and without the use of the device, to determine whether application of this technology translated into any material procedural savings.

Methods The records of 208 single-level TLIF procedures in a single hospital were reviewed. Surgical time, length of hospital stay, blood loss, infection rate, and other parameters were compared for the cases where the device was used (device group; $n=143$ ) and cases which used standard tools (control group; $n=65$ ). The cost per unit of each element was derived from the literature, online resources, and the hospital's financial department.

Results The analysis revealed a shorter surgery duration in the device group ( $23 \mathrm{~min}$, after controlling for procedure year and patient characteristics; statistically significant at $p<0.001)$ and lower complication and readmission rates $(p=0.67$ and $p=0.21$, respectively) associated with the use of the device, leading to a statistically significant cost reduction of approximately 2060 US dollars (US\$) $(p<0.01)$.
\end{abstract}

Conclusion The study suggests that use of the device may lead to a cost reduction and shorter procedure without deteriorating the clinical outcome.

\section{Key Points for Decision Makers}

Spinal procedures are commonly performed, and their rate will continue to rise as the population ages.

Improving procedure outcome and reducing its cost can be beneficial to patients, hospitals and insurers.

Devices aiming to shorten procedure time and reduce complication rates, such as the studied device, may substantially reduce procedure cost.

Michael A. Millgram

research@isc.co.il

1 Center for Spine Care, Dallas, TX 75287, USA

2 Israel Spine Center, Assuta Hospital, Assuta Medical Centers, 69710 Tel Aviv, Israel

3 Texas Back Institute, Plano, TX 75093, USA

4 Polyclinique Bordeaux Nord Aquitaine, 33077 Bordeaux, France

\section{Introduction}

The rate of spinal surgeries in the United States has increased significantly over the past 30 years and continues to grow as new improvements are introduced $[1,2]$. The number and proportion of older patients $(>65$ years of age), individuals who are more prone to degenerative spinal diseases, is expected to grow further [3], thus increasing the overall expenditure on spinal surgeries. As reimbursement policies shift from fee-for-service to bundled payment models, there is a common incentive for insurers, hospitals, and patients to reduce procedure cost while still maintaining efficacy and safety. Clinical outcome is tightly linked with procedure cost, as complications and readmissions can be costly to all stakeholders and have the potential to reduce or eliminate overall profit to the facility [4].

In this study, we focus upon the key cost drivers of transforaminal lumbar interbody fusion (TLIF), a spinal procedure commonly performed in the USA [5]. Here we report our experience with a new device (Dreal ${ }^{\circledR}$, Carevature Medical 
Ltd., Rehovot, Israel) used during TLIF procedures. This device is a high-speed drill-like device with a 3-mm diameter cutting tip, angled at $45^{\circ}$, rotating at up to 60,000 rotations/min, and shielded dorsally (Fig. 1). The device is used to improve the endplate preparation stage of the TLIF procedure and is designed to reduce surgical time and significantly lower the number of device passes that are required (see Fig. 2) as compared to conventional manual tools such as pituitary rongeurs, intervertebral shavers, and curettes. The design is intended to reduce the volume of nucleus tissue and residual endplate cartilage remaining in the disc space, potentially improving fusion rates and reducing the need for revision surgeries. The device is approved by the Food and Drug Administration (FDA) for bone removal and by the regulatory authorities in Israel, where this study was conducted. The device is designed to decorticate the endplate and has three unique features that are an improvement over existing instruments. In combination, these features are designed to shorten the time required for endplate preparation, and to reduce the number of required instrument passes (which are associated with reduced complication rates [6]). First, the distal end (tip) is curved to improve access to all four quadrants of the intervertebral space. Second, the device has integrated irrigation which combines with the morselized disc and comes out easily with standard suction. Finally, the high-speed rotating cutter is shielded on one side to protect adjacent structures. The shield also limits the penetration depth of the rotating cutter into the endplate to $0.1 \mathrm{~mm}$ to preserve structural integrity while removing the outer layer down to bleeding bone. As with any procedure performed in close proximity to neural structures, the surgeon should be familiar with the relevant anatomy and work according to its limitations.

Entering into this study, it was hypothesized that device use could shorten the operating room (OR) time and lower the complication rate, which could in turn lead to a reduced procedure cost, without deteriorating the clinical outcome. As the device is single-use and disposable, an economic

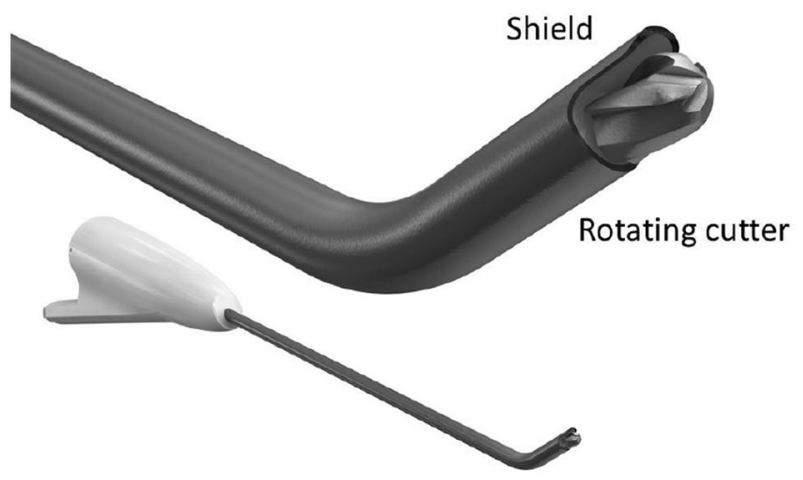

Fig. 1 The Dreal ${ }^{\circledR}$ device (bottom) and an expanded view of the distal tip (top)

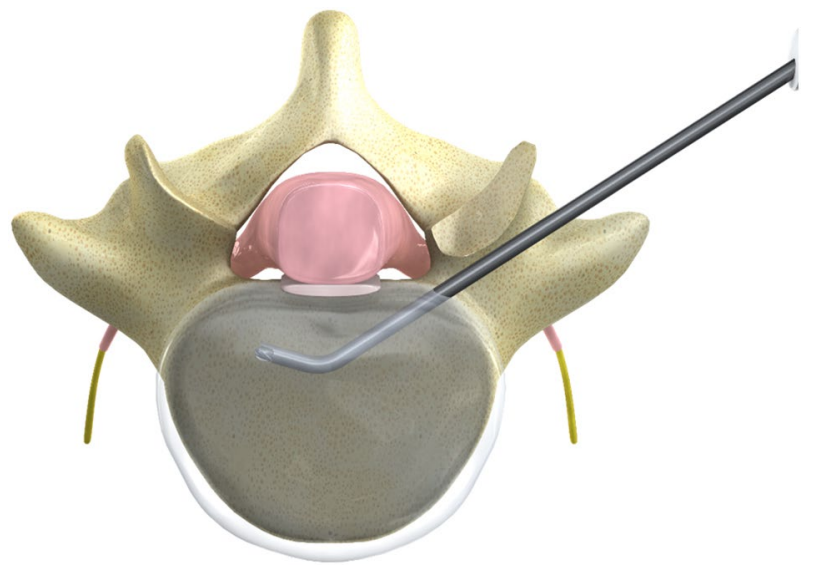

Fig. 2 An illustration of the device inside the disc space in a transforaminal lumbar interbody fusion setting

analysis of the potential savings due to its use was desired in order to determine the economic viability of its use. The primary aim of this study was to evaluate whether use of the device resulted in reduced hospitalization cost in TLIF procedures compared with utilization of traditional tools and methods.

\section{Methods}

\subsection{Retrospective Chart Review}

The records of 319 TLIF procedures performed in a single institution (Israel Spine Center, Assuta Medical Centers, Tel Aviv, Israel) during 2012-2019 were reviewed for this study. All procedures were conducted by members of the same team of four experienced surgeons in a single institution in order to minimize bias due to local policies and surgeon preferences. Initial TLIF experience with the device was by one surgeon in 2014, and device use has subsequently gradually expanded to other surgeons. Polyetheretherketone (PEEK) cages and autografts were used in all operations. Spinal systems depended on surgeon choice and included Armada (Nuvasive, San Diego, CA), Denali (K2M, Leesburg, VA, USA), Solera (Medtronic, Minneapolis, Minnesota USA), and Zodiac (Alphatec Spine, Carlsbad, CA). The following exclusion criteria were used to ensure all procedures were consistent with the exception of device use, and to reduce potential confounding factors: multiple-level surgery; revision surgery; procedures performed by guest surgeons; and patients with existing spondylosis or major comorbidities (such as spinal tumors). As a result, only single-level TLIF procedures, without additional surgical procedures, were compared. Institutional review board approval was obtained for retrospective chart review. The Strengthening 
the Reporting of Observational Studies in Epidemiology (STROBE) and Consolidated Health Economic Evaluation Reporting Standards (CHEERS) guidelines were implemented in the preparation of this study [7, 8].

The cost of the procedure to the hospital is composed of the costs of the surgery, the hospitalization, and the cost of any subsequent complications. Therefore, parameters affecting the costs of these elements were extracted from patient records. In addition, the clinical outcome of the procedures was also evaluated in order to ensure that the procedures conducted with the device did not have any negative effect on the clinical outcome.

\subsubsection{Available Parameters}

Clinical, operative, and hospitalization parameters were extracted from patient records. Clinical outcome was assessed using visual analog scale (VAS), Oswestry Disability Index (ODI), and SF-36 questionnaires, as commonly accepted for this procedure. Clinical outcome changes were calculated only for patients who had both pre-operative and postoperative questionnaires (at least 3 months of follow-up) available (10-12 patients in the control group and 31-35 patients in the device group, depending on the type of questionnaire). The physical component summary (PCS) and the mental component summary (MCS) scores were calculated from the SF-36 questionnaires based on published metrics [9].

Surgery duration was defined as the time reported between the initial incision and final sutures. In 21 records, this time was missing, so these were excluded from the average surgery duration calculations. OR time was assumed to be longer than surgery duration by a fixed unknown constant (i.e., room turnover time), which would not be affected by use of this device. For this reason, surgery duration differences between the device group and control group were used to estimate the changes in OR time. Blood loss records were based on surgeon estimations during the procedure. The number of instrument passes during the nucleus removal stage was extracted from the records where available. These data were captured for 63 procedures where the device was used, but were not available for control cases where conventional tools were used. For this reason, number of device passes for the control group was pulled from several literature references.

Baseline procedure cost, including diagnostic tests, implant costs, surgeon fees, surgical supplies, etc., was considered to be the same for both groups, as the device would not affect these parameters. Additional costs were calculated by determining the individual cost components, such as surgery and hospitalization durations, and multiplying them by the average cost per unit of each component. In cases that were missing surgery time records, average OR time was used for each respective group. The cost increase of the complications and readmissions cases was calculated and presented in two different ways. First, it was calculated using estimations provided by the hospital's financial department, representing expenditure for the hospital based on the added procedures, drugs, and tests indicated in the patients' records. Additionally, a more general estimation was performed for the USA, based on costs derived from a literature review.

The baseline and overall costs could not be made publicly available, and therefore only the cost difference was calculated and presented.

Since the purchasing price of the device varies between countries and is considered commercially confidential, it was excluded from the calculation of the cost difference. The calculated cost difference represents the potential cost reduction for the hospital, which should be higher enough than the device price in order to justify its purchase.

All the clinically meaningful parameters that were available from the patient records were extracted to be used as factors in the statistical analysis: the patient's age, sex, smoking status, operated level, and comorbidities. A patient was considered to have a major comorbidity if the record stated one of the following conditions: hypertension, ischemic heart disease, diabetes, cerebrovascular accident (CVA), peptic ulcer disease, osteoporosis, and chronic obstructive pulmonary disease (COPD). The years in which the procedures were performed were extracted in order to account for changes in hospitalization policy, improved facilities, and other long-term trends.

\subsection{Literature Review: Cost of Hospitalization Components}

Table 1 presents the cost per unit of different components affecting the overall cost, extracted from the literature [10-26], available online resources [5, 27], and the financial department of the hospital. The conversion rates used were the conversion rates on January 15th, 2020: US\$1 (US dollar) $=€ 0.9$, US $\$ 1=£ 0.77$, and US $\$ 1=3.46$ Israeli new shekels (ILS).

Costs reported for previous years or in non-US currencies are presented in US dollars and adjusted to 2020 costs using an inflation calculator [28]. The literature review was not limited by year due to low availability of data in some fields. It is important to note that this study discusses actual costs and not charges, which are the amounts requested from the patient or the insurer. 


\subsubsection{Cost of Operating Room Time}

The cost of the surgical procedure itself is one of the main components of the hospitalization cost. Some of the surgical costs are fixed (such as equipment or implants), and some are variable and depend on procedure duration (such as personnel and anesthesia). Cost estimations for the fixed and variable costs appear in Table 1, as well as references for the costs of anesthesia and personnel that may be added to these amounts. For the US cost analysis, a cost of US $\$ 40.48 / \mathrm{min}$ was used, which includes US $\$ 10$ as fixed costs (compared with the referenced range of US\$8.8-US\$11.75), US $\$ 23$ as variable costs (compared with the referenced range of US\$20-US\$26.1), US\$3.61 for anesthesia personnel and supplies, and US\$3.87 for the surgeon fee, as described in Table 1.

\subsubsection{Length of Stay}

In general, the cost per day changes throughout the hospitalization and reduces to the cost of "room and board" on the last day, which is the least expensive [15]. This is the day that can potentially be saved due to an improved procedure. The literature review did not uncover recent articles which describe the cost of a hospitalization day without added procedures. However, the cited amount is similar to the cost estimation of the financial department.

\subsubsection{Complications}

Complications, such as infections or dural tears, increase the hospitalization cost since they require treatment and attention during and after the surgery and may lead to additional, more serious, complications. Furthermore, surgical site infections (SSIs) and urinary-tract infections following spinal procedures are considered Provider Preventable Conditions which do not justify additional reimbursement [29] and are therefore important factors in cost analyses.

\subsubsection{Blood Loss}

The cost of blood was calculated as the acquisition cost of a blood unit [30] divided by 0.37 , the relative share of the acquisition cost in the total handling cost of a blood unit by the hospital [31], resulting in the overall blood unit cost to the hospital. The ratio between the blood lost and the blood units used was calculated from the literature [32] and was found to be 0.002 (blood units $/ \mathrm{ml}$ blood loss). This ratio was multiplied by the cost of the blood unit to estimate the cost of blood loss.

\subsection{Statistical Methods}

Statistical analysis was conducted using statistical software (JASP 0.10, JASP Team, 2019). A one-way analysis of covariance (ANCOVA) was conducted to compare length of stay, OR time, and blood loss depending on the device used, controlling for procedure year and patient age, sex, smoking status, presence of major comorbidities $(n \geq 1)$, and operated level, followed by post hoc analysis of statistically significant variables. The paired Student $t$ test was used to compare preoperative and postoperative clinical outcome scores. Other changes were described using the independent sample Student's $t$ test and the Chi-squared test. The Mann-Whitney $U$ test and the Kruskal-Wallis nonparametric test were used to compare overall costs due to outliers and unverified distribution normality. All tests were two-tailed. A cutoff $p$ value of 0.05 was set to determine statistical significance.

\section{Results}

TLIF records of 319 procedures were reviewed for this study. A total of 111 procedures were excluded (79 device group, 32 control group), and 208 procedures were included in the study. The study group consisted of 143 procedures that were performed using the new device, and the control group contained 65 procedures where traditional tools and methods were used. The demographic data of the patients in both groups is presented in Table 2. As the table shows, there was no statistically significant difference between both groups in any of the evaluated parameters: age, sex, smoking status, operated level, indication, existing comorbidities, or preoperative clinical scores, with the following exception-the preoperative SF-36 MCS score was significantly higher (worse) in the control group. This difference may be due to the relatively small number of patients with both the preoperative and postoperative questionnaires available for this group who completed the SF-36 questionnaire.

Patient age in the control group was higher by 3 years compared with the device group $(p=0.06)$. As patient age can affect the observed parameters, the age was included as a covariate to the statistical analysis to account for these effects. The differences in the prevalence of comorbidities between both groups were not statistically significant $(p>0.13)$. However, since comorbidities such as diabetes or ischemic heart disease can potentially affect hospitalization and increase the risk of complications, the presence of comorbidities was therefore included in the ANCOVA analysis as well.

The control group had four complications (6.2\%) and two readmissions (3.1\%). The device group had four complications $(2.8 \%)$ and three readmissions (2.1\%). The 


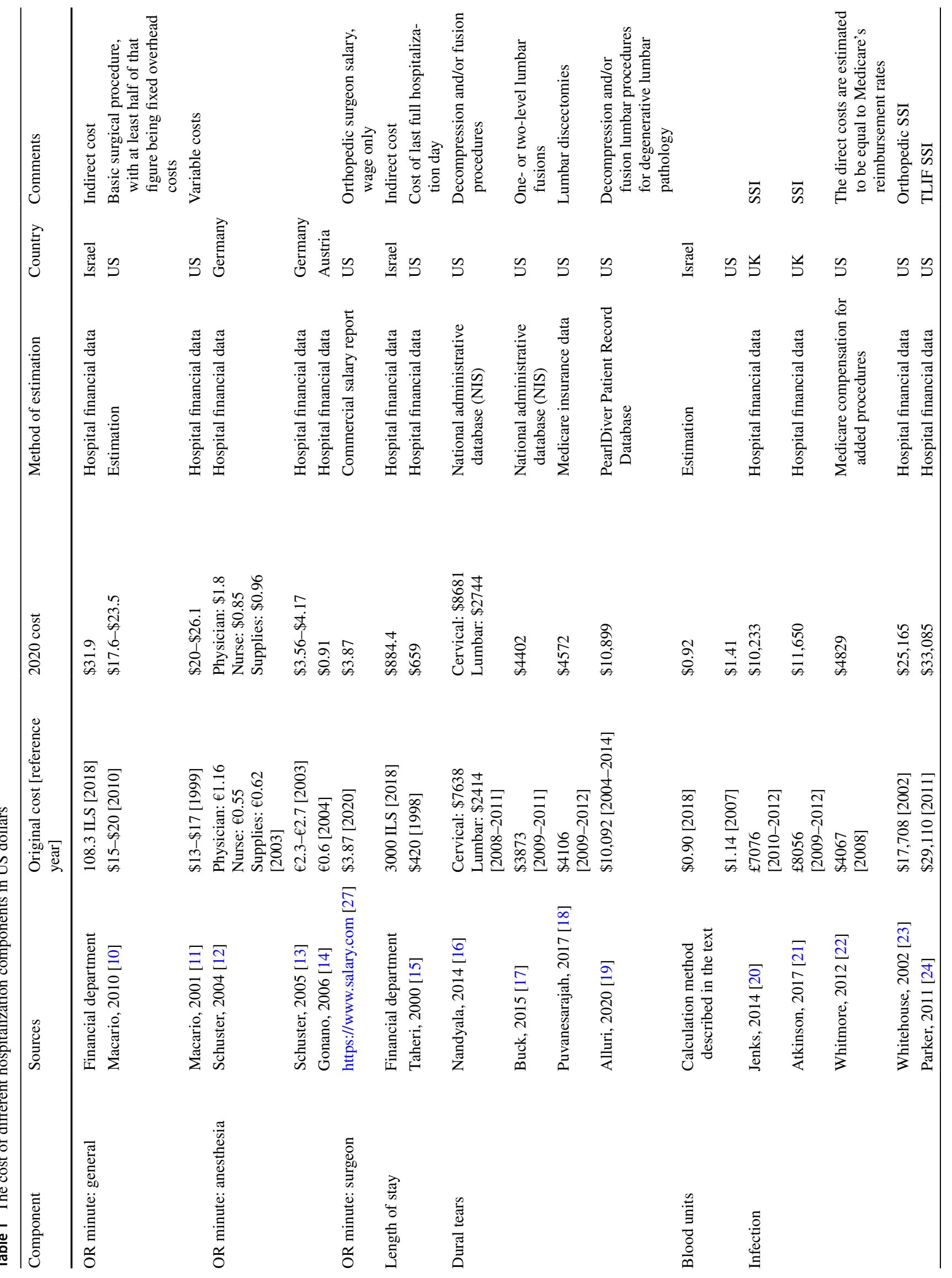




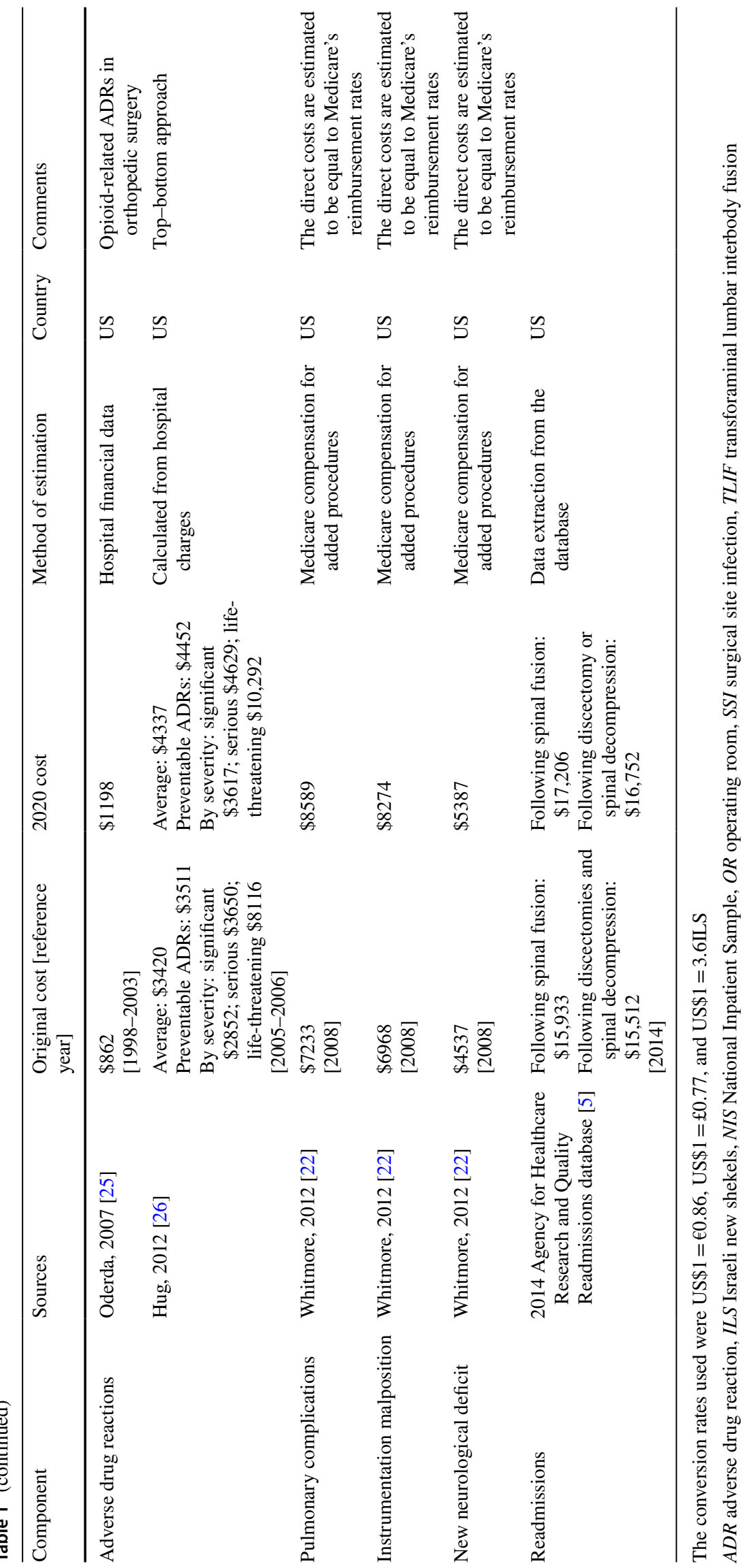


Table 2 Patient demographic data

\begin{tabular}{|c|c|c|c|}
\hline & Control group & Device group & $P$ \\
\hline Number of patients & 65 & 143 & \\
\hline Average age (range) & $\begin{array}{l}49.2 \text { years }(\mathrm{s} . \mathrm{d} .=11.4, \\
\text { range } 24-77, n=65)\end{array}$ & $\begin{array}{l}46 \text { years }(\text { s.d. }=11.6 \text {, range } \\
21-82, n=143)\end{array}$ & 0.06 \\
\hline Sex & & & 0.29 \\
\hline Male & $40(62 \%)$ & $76(53 \%)$ & \\
\hline Female & $25(38 \%)$ & $67(47 \%)$ & \\
\hline Smoking status & & & 0.49 \\
\hline Yes & $15(23 \%)$ & $40(28 \%)$ & \\
\hline No & $50(77 \%)$ & $103(72 \%)$ & \\
\hline Operated level & & & 0.07 \\
\hline L1-L2 & $1(1.5 \%)$ & $1(0.7 \%)$ & \\
\hline L2-L3 & $2(3.1 \%)$ & $5(3.5 \%)$ & \\
\hline L3-L4 & $7(10.8 \%)$ & $10(7.0 \%)$ & \\
\hline L5-L5 & $39(60.0 \%)$ & $62(43.4 \%)$ & \\
\hline L5-S1 & $16(24.6 \%)$ & $65(45.5 \%)$ & \\
\hline Indication & & & 0.78 \\
\hline Leg pain/weakness & $48(73.8 \%)$ & $97(67.8 \%)$ & \\
\hline Lower back pain & $1(1.5 \%)$ & $5(3.5 \%)$ & \\
\hline Lower back and leg pain & $8(12.3 \%)$ & $12(8.4 \%)$ & \\
\hline Lower back pain and sciatica & $7(10.8 \%)$ & $24(16.8 \%)$ & \\
\hline Sciatic pain & $1(1.5 \%)$ & & \\
\hline Sciatica and leg weakness & & $2(1.4 \%)$ & \\
\hline Leg pain and spinal claudication & & $1(0.7 \%)$ & \\
\hline Back pain and spinal claudication & & $1(0.7 \%)$ & \\
\hline Missing & & $1(0.7 \%)$ & \\
\hline \multicolumn{4}{|l|}{ Comorbidity } \\
\hline Hypertension & $10(15.4 \%)$ & $12(8.4 \%)$ & 0.13 \\
\hline Diabetes & $8(12.3 \%)$ & $9(6.3 \%)$ & 0.14 \\
\hline Ischemic heart disease & $6(9.2 \%)$ & $7(4.9 \%)$ & 0.23 \\
\hline CVA & $0(0 \%)$ & $2(1.4 \%)$ & 0.34 \\
\hline Peptic ulcer & $2(3.1 \%)$ & $2(1.4 \%)$ & 0.41 \\
\hline Osteoporosis & $1(1.5 \%)$ & $0(0 \%)$ & 0.14 \\
\hline COPD & $1(1.5 \%)$ & $0(0 \%)$ & 0.14 \\
\hline \multicolumn{4}{|l|}{ Preoperative clinical outcome scores } \\
\hline VAS back & $7.2($ s.d. $=2.3, n=11)$ & $8.1($ s.d. $=2.9, n=34)$ & 0.35 \\
\hline VAS leg & 7.8 (s.d. $=2.6, n=11)$ & $7.5($ s.d. $=2.1, n=34)$ & 0.68 \\
\hline ODI & 48.5 (s.d. $=17.3, n=12)$ & $54.1($ s.d. $=17, n=35)$ & 0.3 \\
\hline SF-36 PCS & $16.4($ s.d. $=19.2, n=10)$ & $16.2($ s.d. $=13.9, n=31)$ & 0.98 \\
\hline SF-36 MCS & $65.6($ s.d. $=22, n=10)$ & $47.1($ s.d. $=25.3, n=31)$ & 0.04 \\
\hline
\end{tabular}

$C O P D$ chronic obstructive pulmonary disease, CVA cerebrovascular accident, MCS/PCS mental/physical component summary, $O D I$ Oswestry Disability Index, s.d. standard deviation, VAS visual analog scale complication and readmission descriptions and their estimated costs are detailed in Table 3.

One-way ANCOVA demonstrated that both the device group and the operation year were both statistically significant factors affecting the OR time and blood loss after controlling for patient age, sex, smoking status, presence of major comorbidities, and operated level. The presence of comorbidities was the only statistically significant factor affecting the length of stay. Post-hoc analysis revealed that the controlled difference of OR time between the device and control groups was $23.2 \min (p<0.001)$. The controlled difference in blood loss was $133 \mathrm{ml}$ in favor of the device group $(p<0.01)$. However, this difference is not clinically meaningful.

The only significant factor found to affect the length of stay was the presence of comorbidities $(p<0.01)$. Post-hoc analysis revealed an increase of 0.85 days for patients with existing comorbidities. 
The Kruskal-Wallis test on the procedure costs suggested that the device is a statistically significant factor affecting the overall cost $(p<0.001)$. The Mann-Whitney $U$ test demonstrated a statistically significant reduction in the average procedure cost, estimated at US\$2060 based on data derived from the financial department and US $\$ 2041$ based on the literature US data $(p<0.01$ for both). Parameter changes and the overall cost-reduction appear in Table 4. Figure 3 shows the overall costs above a common baseline, as estimated by the financial department for both groups, along with the $95 \%$ confidence intervals calculated by the statistical software (JASP). As the figure shows, the difference between both groups is substantial, with minimal overlap of the $95 \%$ confidence intervals. The cost reduction was substantially higher than the purchase cost of the device, and therefore device use results in a net saving of the majority of this amount.

The preoperative and postoperative clinical outcome scores are reported in Table 5. As the table shows, the paired $t$ test analysis revealed a statistically significant improvement between the preoperative and postoperative back and leg pain scores of both the device and control groups $(p<0.01)$. A statistically significant improvement was noted in the device group's ODI and SF-36 PCS and MCS scores, and in the control group's SF-36 PCS score $(p \leq 0.01)$. The control group demonstrated improved ODI score and deteriorated
SF-36 MCS score, but both changes were not statistically significant, probably due to the small sample size and the relatively high preoperative SF-36 MCS score, as noted above.

Table 6 shows the clinical score improvements in both groups. As the table shows, the differences between the improvements achieved in the device group and the control group were not statistically significant in any of the clinical outcome scores ( $p=0.07-0.9)$, suggesting the device did not significantly affect the clinical outcome, as expected.

Both groups included patients who suffered from SSIs that later led to readmissions, one in the device group $(0.8 \%)$ and one in the control group (1.9\%).

The nucleus removal stage required, on average, 2.83 instrument passes.

One patient in the control group (1.5\%) and none of the device group $(0 \%)$ were readmitted for an additional surgery aimed to remove remaining disc fragments. The patient suffered from a deterioration in leg weakness after the original procedure. A magnetic resonance imaging (MRI) scan demonstrated remaining disc fragments, and the patient was readmitted for a revision surgery 1 month after the original procedure. Two patients in the device group (1.4\%) were admitted during the following years for a revision surgery due to pseudoarthrosis. The difference between these rates was not statistically significant $(p=0.94)$.

Table 3 Complications, readmissions and their cost increase (beyond the original hospitalization length of stay and operating room cost, in US dollars) in the TLIF device and control groups

\begin{tabular}{|c|c|c|c|c|}
\hline Group & $\begin{array}{l}\text { Complication/readmission } \\
\text { description }\end{array}$ & Main cost elements & $\begin{array}{l}\text { Cost increase estimation } \\
\text { by the financial depart- } \\
\text { ment }\end{array}$ & $\begin{array}{l}\text { Cost increase estimation using the } \\
\text { literature review results }\end{array}$ \\
\hline \multirow[t]{4}{*}{ Control } & SSI & $\begin{array}{l}\text { Readmission for } 52 \text { days, addi- } \\
\text { tional surgery, extensive use of } \\
\text { drugs and antibiotics }\end{array}$ & $\$ 61,970$ & $\begin{array}{l}\$ 62,740=\$ 33,085 \text { (TLIF } \\
\text { SSI) }+\$ 29,655 \text { (additional hos- } \\
\text { pitalization days) }\end{array}$ \\
\hline & Remaining disc fragments & Readmission, additional surgery & $\$ 12,212$ & $\begin{array}{l}\$ 17,206 \text { (spinal fusion average } \\
\text { readmission cost) }\end{array}$ \\
\hline & Dural tear and infection & $\begin{array}{l}\text { Drain placement, multiple } \\
\text { readmissions, additional MRI, } \\
\text { antibiotics }\end{array}$ & $\$ 14,465$ & $\begin{array}{l}\$ 13,628=\$ 4402 \text { (tear in } \\
\text { one- and two-level lumbar } \\
\text { fusions) }+\$ 9226 \text { (cost of } 14 \text { days } \\
\text { of hospitalization during read- } \\
\text { missions) }\end{array}$ \\
\hline & Retroperitoneal hematoma & Observation & & \\
\hline \multirow[t]{5}{*}{ Device } & Dural tear (not device related) & $\begin{array}{l}\text { Readmission for } 6 \text { days, addi- } \\
\text { tional surgery }\end{array}$ & $\$ 6179$ & $\begin{array}{l}\$ 4402 \text { (tear in one- and two-level } \\
\text { lumbar fusions) }\end{array}$ \\
\hline & Dural tear (not device related) & Observation & & \\
\hline & Suspected CSF leak & Drain placement and observation & & \\
\hline & $\begin{array}{l}\text { Rectal abscess, potentially due } \\
\text { to enema use at the original } \\
\text { hospitalization }\end{array}$ & Readmission for 1 day & $\$ 884$ & $\$ 659$ \\
\hline & SSI & $\begin{array}{l}\text { Readmission for } 11 \text { days, addi- } \\
\text { tional surgery, extensive use of } \\
\text { drugs and antibiotics }\end{array}$ & $\$ 15,316$ & $\$ 33,085$ (TLIF SSI) \\
\hline
\end{tabular}

CSF cerebrospinal fluid, MRI magnetic resonance imaging, SSI surgical site infection, TLIF transforaminal lumbar interbody fusion 
Table 4 Hospitalization and economical changes due to the use of the new device

\begin{tabular}{|c|c|c|c|}
\hline & Control & Device & Difference due to the device \\
\hline OR time [min] & $\begin{array}{c}1: 46: 40 \text { (s.d. }=0: 28: 52 \text {, range } \\
1: 03: 00-4: 15: 00, n=50)\end{array}$ & $\begin{array}{c}1: 35: 39 \text { (s.d. }=0: 19: 16, \text { range } \\
0: 23: 00-2: 54: 00, n=137)\end{array}$ & $\begin{array}{l}23.2 \text { min (post hoc, controlling } \\
\text { for year, age, sex, presence of } \\
\text { comorbidities, smoking status, } \\
\text { and operated level, } p<0.001, \\
95 \% \text { CI } 13.4-33 \text { ) }\end{array}$ \\
\hline $\begin{array}{l}\text { Original hospitalization LOS } \\
\text { [days] }\end{array}$ & $\begin{array}{l}5.54 \text { (s.d. }=1.7, \text { range } 3-12, \\
n=65)\end{array}$ & $5.1($ s.d. $=1.2$, range $2-8, n=143)$ & Not statistically significant \\
\hline Blood loss [ml] & $\begin{array}{l}277 \text { (s.d. }=200, \text { range } 0-800, \\
\quad n=65)\end{array}$ & $\begin{array}{l}229 \text { (s.d. }=251, \text { range } 0-1500 \\
\quad n=143)\end{array}$ & $\begin{array}{l}133.2 \text { (post hoc, controlling for } \\
\text { year, age, sex, presence of } \\
\text { comorbidities, smoking status, } \\
\text { and operated level, } p=0.005, \\
95 \% \text { CI } 40-227 \text { ) }\end{array}$ \\
\hline Complications/readmissions [\%] & $6.2 \% / 3.1 \%$ & $2.8 \% / 2.1 \%$ & $-55 \% /-32 \%(p=0.21 / p=0.67)$ \\
\hline Instrument passes & 29-70 (literature data) & $2.83($ s.d. $=1.2$, range $2-8)$ & $>26$ \\
\hline Overall cost [IL] & - & - & US\$2060 $(p<0.01)$ \\
\hline Overall cost [US] & - & - & US\$2041 $(p<0.01)$ \\
\hline
\end{tabular}

$C I$ confidence interval, IL Israel, LOS length of stay, OR operating room, s.d. standard deviation

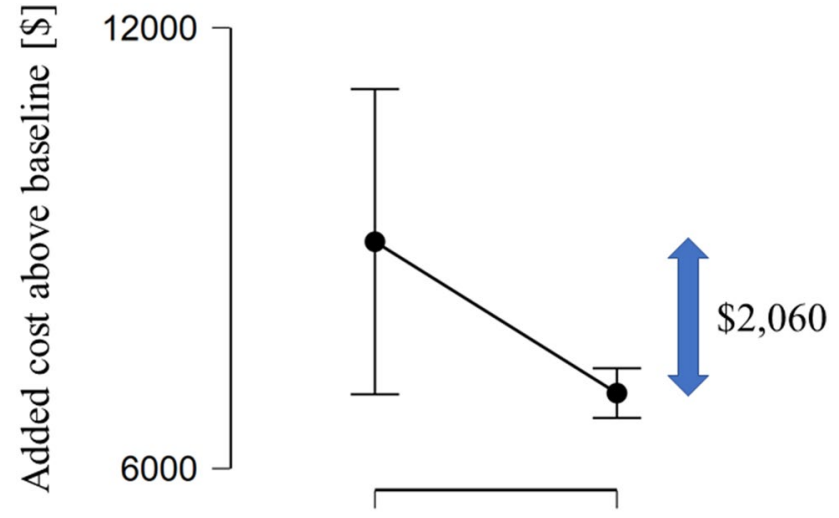

\section{Control Device}

Fig. 3 Overall costs (US dollars) above a common baseline for the control and device groups, as estimated by the financial department. The error bars represent the $95 \%$ confidence interval

\section{Discussion}

Incorporating a new device to a clinical setting requires constant evaluation of the clinical and economic effects of its use. The current study used patient records and the cost per unit of different hospitalization aspects to calculate the changes in TLIF procedure cost, operative and postoperative parameters, upon utilizing the new device. As hypothesized, device use resulted in statistically significant reductions in cost and OR time. The clinical outcome scores did not change significantly.

This is a retrospective study and therefore by nature more prone to bias than a controlled prospective study. However,
Table 5 Preoperative and postoperative clinical outcome scores: averages (standard deviation)

\begin{tabular}{lccr}
\hline & Preoperative & Postoperative & $P$ value \\
\hline Control group $(n=12)$ & & & \\
VAS back & $8.1(2.9)$ & $4.7(3.6)$ & $<0.01$ \\
VAS leg & $7.8(2.6)$ & $4.4(3.8)$ & $<0.01$ \\
ODI & $48.5(17.3)$ & $35.7(25.7)$ & 0.13 \\
SF-36 PCS & $16.4(19.2)$ & $42(22.5)$ & $<0.01$ \\
SF-36 MCS & $65.6(22)$ & $53.4(29.3)$ & 0.37 \\
Device group $(n=35)$ & & & \\
VAS back & $7.2(2.3)$ & $5(2.33)$ & $<0.01$ \\
VAS leg & $7.5(2.1)$ & $4.2(3.3)$ & $<0.01$ \\
ODI & $54.1(17)$ & $36.1(21.1)$ & $<0.01$ \\
SF-36 PCS & $16.2(13.9)$ & $36.2(22.5)$ & $<0.01$ \\
SF-36 MCS & $47.1(25.3)$ & $62.8(28)$ & 0.01 \\
\hline
\end{tabular}

MCS/PCS mental/physical component summary, ODI Oswestry Disability Index, $V A S$ visual analog scale

Table 6 Improvement of clinical outcome scores comparison between groups: averages (standard deviation)

\begin{tabular}{lccl}
\hline & $\begin{array}{c}\text { Control group } \\
\text { improvement }\end{array}$ & $\begin{array}{l}\text { Device group } \\
\text { improvement }\end{array}$ & $P$ value \\
\hline VAS back & $3.4(3.3)$ & $2.2(2.5)$ & 0.27 \\
VAS leg & $3.4(3.3)$ & $3.3(3.5)$ & 0.9 \\
ODI & $12.8(26.7)$ & $18(19.6)$ & 0.54 \\
SF-36 PCS & $25.5(14.7)$ & $19.9(25)$ & 0.4 \\
SF-36 MCS & $-12.2(40.5)$ & $15.7(31.8)$ & 0.07 \\
\hline
\end{tabular}

MCS/PCS mental/physical component summary, ODI Oswestry Disability Index, VAS visual analog scale 
the study was designed to reduce the risk of bias and the effect of potential confounding factors by including only single-level procedures from a single center, conducted by the same team of surgeons and under similar conditions and hospital policies.

A shorter procedure time and fewer complications can translate to reduced costs for either the hospital or the payer, depending on the reimbursement model. In this study, the reimbursement model was the same for both groups, as they were all conducted during the time period, and the surgeons in the facility did not have a financial incentive to reduce the OR time or the length of stay for patients in one group compared with the other.

The main difference between the groups was the introduction of the new device, and therefore it was assumed that it would be the main cause for any changes observed between them.

Improved endplate preparation can consequently lead to reduced pseudoarthrosis rates [33]. The difference in reoperation rates due to incomplete disc removal and pseudoarthrosis that was seen in this study was not statistically significant. A larger sample size is required to test the effect of the studied device on this rate. In addition, since the use of supplemental biologics is associated with improved fusion [34], it may be possible that improving the endplate preparation will reduce the need for these expensive materials, which could potentially further increase the cost reduction. The cost difference due to these parameters was not examined in this study and will be the subject of future research.

A reduction in OR time can lead to a reduction in infection rates [35] and complication rates [36]. The observed reduction in OR time in this study represents a reduction of up to $25 \%$ of surgical duration and can therefore potentially lead to the observed, although not statistically significant, reduction in infection and complication rates. The time reduction represents an even higher relative reduction in the duration of muscle retraction, which is correlated with reduced muscle function [37] and consequently with deteriorated procedure outcome [38]. Although not statistically significant in the current study, a reduction in the length of stay can further contribute to a reduced rate of infections.

The number of instrument passes required for the endplate preparation stage was 2.83 . Previously published TLIF studies estimated the required number of instrument passes for traditional tools and methods to be 29-70 [39-43]. The comparison of the number of instrument passes should be conducted in the same setting by the same surgeons. However, the substantial difference between the devices suggests that the reduction cannot be attributed to different practices and settings alone and is also likely to be affected by the use of the device. The authors believe that this positively affects the safety of the procedure in terms of risk to the neural elements and potential infections. In this study, $40 \%$ $(2 / 5)$ of the readmissions were caused by SSIs, and could be potentially avoided by reducing further the number of instrument passes [6]. In addition, the use of a single-use sterilized device, such as the studied device, can further reduce the infection rates, as traditional surgical tools are sterilized in the hospital and more exposed to infections.

The reduction in the number of required instrument passes is in accordance with similar literature studies evaluating the efficacy of dedicated devices for disc space preparation compared with traditional tools and methods. In these studies, the preparation stage required only six to 20 instrument insertions, a number substantially lower than that for the equivalent controls of 29-70 [39-43]. As these studies demonstrate, along with the current study, the potential for reducing the number of instrument passes is considerable.

This study was conducted in a single center and therefore represents best the effect on the practices in this institution. However, the authors believe that the results can be generalized to represent the potential outcome in other facilities and in different countries for several reasons. First, the TLIF procedure conducted by the surgeons was not modified compared with common practice, and therefore any changes to the surgical routine due to the device are expected to be the same when conducted by other surgeons. Second, due to the design of the device, the number of required instrument passes is expected to be lower compared with traditional tools for other surgeons in other facilities as well, and therefore a similar change in complications is expected to occur as well.

The calculated cost reduction was very similar for both calculation methods. The minor difference can be attributed to several causes. First, the financial department's estimation was more patient specific and could therefore consider more accurately the actual cost components. Second, the costs in each country may be different, as Table 1 shows.

The cost reduction is substantial when compared with the overall procedure cost as evaluated in the available literature. The mean estimated direct cost of a TLIF procedure for hospitals was estimated at US $\$ 23,550$ by Singh et al. [44] and at US $\$ 25,452$ for the hospital costs and surgeon fee by Kim et al. [45], whereas Parker et al. estimated the direct hospitalization costs at US\$10,770 and the 2-year direct costs at US $\$ 28,442$ [46]. A potential cost reduction of US $\$ 2000$ is therefore equivalent to approximately $8 \%$ of the overall costs. The cost of the device was not included in the cost reduction analysis. Since the device cost is substantially lower than this amount, it can facilitate a substantial saving to the hospital.

The complication and readmission rates reported in the literature vary between studies. Studies on the National Surgical Quality Improvement Program (NSQIP) database found a $5.51 \%$ readmission rate within 30 days [47] and a 
$4 \%$ major complication rate [48], similar to Chan et al., who reported a 3.5\% 3-month readmission rate [49]. These rates are relatively similar to the readmission rate calculated for the control group in the current study.

These results indicate that using the device can be financially justified if its price is not higher than the amount of cost reduction, compared with the cost of the alternative devices used for the endplate preparation and especially those designed for nucleotomy only. The list price per unit of the device was considerably lower than the savings, leading to an overall cost reduction to the hospital.

\subsection{Study Limitations}

This study is retrospective, utilizing available patient records. Conducting a prospective controlled randomized study would improve the validity of the conclusions derived from the current study and may be conducted in the future.

The cost per unit amounts are derived from studies conducted in different facilities, countries, and years. However, they are relatively similar and therefore were considered suitable for these estimations. The weighed cost of the complications was higher for the USA in both the control and device groups, but the difference was similar.

The group sizes were insufficient for a statistically significant assessment of complication and readmission rates. For example, in the current study, the dural tear incidence was slightly higher in the device group ( $2 \%$, including one case of suspected cerebrospinal fluid leak) compared with the control group (1.5\%). However, a previous study reported a lower device-related dural tear incidence for this device $(0.4 \%)$ when compared with the $2.91 \%$ device-related incidence associated with the commonly used high-speed drill and Kerrison rongeur [50]. The sample size should be increased in future studies in order to allow a more valid comparison of complication and readmission rates.

As the settings can affect the number of instrument passes, the clinical-setting comparison is limited by the different sources of the control and the device group. A controlled comparison is required to validate these results.

Ideally, as surgeons may differ in skill level and technique, adding the operating surgeon as an additional parameter to the statistical analysis was desirable. However, the surgeons in the facility always operate in pairs while only one name appears in the procedure records. Therefore, it was impossible to know retrospectively who the second surgeon in the OR was and who performed the disc preparation part of the procedure, and therefore this parameter was not included. However, it is important to note that all surgeons had been operating together for over a decade before the first procedures included in this study, and therefore they were all very experienced in conducting TLIF procedures and there was no expected difference in skill level between the surgeons or between the same surgeon at different time periods included in the study.

In addition, it is possible that there are other confounding variables which were not examined and affect the comparison and its findings. A future prospective study should include the collection of additional variables, such as both operating surgeons' identity and the patient's body mass index.

The study is based on patient records from a single hospital. While this reduces potential bias due to parameters differing between centers, further studies in additional facilities could improve the validity of the described findings.

\section{Conclusions}

In summary, examination of patient records revealed a statistically significant reduction in OR time and a potential, not statistically significant reduction in length of stay and complication and readmission rates associated with the use of the device, leading to estimated cost savings of approximately US\$2060 per case, which is considerably higher than the device's listed price.

\section{Declarations}

Ethics approval This retrospective chart review study involving human participants was in accordance with the ethical standards of the institutional and national research committee and with the 1964 Helsinki Declaration and its later amendments or comparable ethical standards. The Human Investigation Committee (institutional review board) of the hospital approved this study.

Funding The authors received no specific funding for this work.

Conflict of interest Dr. Millgram, Dr. Guyer, and Prof. Le Huec are consultants for Carevature Medical Ltd., which manufactures the device mentioned in the study. Dr. Ashkenazi is a shareholder and consultant of Carevature Medical Ltd., which manufactures the device mentioned in the study. Dr. Peloza, Mr. Jacobian, and Mr. Kolsky have no conflicts of interest directly relevant to this article.

Code availability Not applicable.

Availability of data and material :The data that support the findings of this study are not publicly available due to them containing information that could compromise patient privacy.

Consent to participate Not applicable.

Consent for publication Not applicable.

Authors' contributions JHP, RD, and JCLH: Manuscript review and editing. MAM: Conducted the surgeries; manuscript review and editing. EJ and DEK: Data acquisition and analysis. EA: Conducted the surgeries, methodology, data analysis, writing and editing of the manuscript. 
Open Access This article is licensed under a Creative Commons Attribution-NonCommercial 4.0 International License, which permits any non-commercial use, sharing, adaptation, distribution and reproduction in any medium or format, as long as you give appropriate credit to the original author(s) and the source, provide a link to the Creative Commons licence, and indicate if changes were made. The images or other third party material in this article are included in the article's Creative Commons licence, unless indicated otherwise in a credit line to the material. If material is not included in the article's Creative Commons licence and your intended use is not permitted by statutory regulation or exceeds the permitted use, you will need to obtain permission directly from the copyright holder. To view a copy of this licence, visit http://creativecommons.org/licenses/by-nc/4.0/.

\section{References}

1. Weinstein JN, Lurie JD, Olson PR, Bronner KK, Fisher ES. United States' trends and regional variations in lumbar spine surgery: 1992-2003. Spine. 2006;31:2707-14.

2. Pannell WC, Savin DD, Scott TP, Wang JC, Daubs MD. Trends in the surgical treatment of lumbar spine disease in the United States. Spine J. 2015;15:1719-27.

3. Ortman JM, Velkoff VA, Hogan H, others. An aging nation: the older population in the United States. Washington, DC: US Census Bureau. 2014;25-1140.

4. Healy MA, Mullard AJ, Campbell DA, Dimick JB. Hospital and payer costs associated with surgical complications. JAMA Surg. 2016;151:823-30.

5. Nationwide Readmissions Database. Healthcare Cost and Utilization Project (HCUP). Agency for Healthcare Research and Quality, Rockville, MD. [Internet]. 2014. https://www.hcup-us. ahrq.gov/db/nation/nrd/nrddbdocumentation.jsp. Accessed 2 Sept 2019.

6. Rihn JA, Gandhi SD, Sheehan P, Vaccaro AR, Hilibrand AS, Albert TJ, et al. Disc space preparation in transforaminal lumbar interbody fusion: a comparison of minimally invasive and open approaches. Clinical Orthopaedics and Related Research ${ }^{\circledR}$. 2014;472:1800-1805.

7. Von Elm E, Altman DG, Egger M, Pocock SJ, Gøtzsche PC, Vandenbroucke JP. The Strengthening the Reporting of Observational Studies in Epidemiology (STROBE) statement: guidelines for reporting observational studies. Ann Intern Med. 2007;147:573-7.

8. Husereau D, Drummond M, Petrou S, Carswell C, Moher D, Greenberg D, et al. Consolidated health economic evaluation reporting standards (CHEERS) - explanation and elaboration: a report of the ISPOR health economic evaluation publication guidelines good reporting practices task force. Value Health. 2013;16:231-50.

9. Jenkinson C. Comparison of UK and US methods for weighting and scoring the SF-36 summary measures. J Public Health. 1999;21:372-376.

10. Macario A. What does one minute of operating room time cost? J Clin Anesth. 2010;22:233-6.

11. Macario A, Dexter F, Traub RD. Hospital profitability per hour of operating room time can vary among surgeons. Anesth Analg. 2001;93:669.

12. Schuster M, Standl T, Wagner JA, Berger J, Reils smann H, am Esch JS. Effect of different cost drivers on cost per anesthesia minute in different anesthesia subspecialties. Anesthesiology. 2004;101:1435-1443.

13. Schuster M, Gottschalk A, Berger J, Standl T. A retrospective comparison of costs for regional and general anesthesia techniques. Anesth Analg. 2005;100:786.
14. Gonano C, Leitgeb U, Sitzwohl C, Ihra G, Weinstabl C, Kettner SC. Spinal versus general anesthesia for orthopedic surgery: anesthesia drug and supply costs. Anesth Analg. 2006;102:524.

15. Taheri PA, Butz DA, Greenfield LJ. Length of stay has minimal impact on the cost of hospital admission. J Am Coll Surg. 2000;191:123-30.

16. Nandyala SV, Elboghdady IM, Marquez-Lara A, Noureldin MNB, Sankaranarayanan S, Singh K. Cost analysis of incidental durotomy in spine surgery. Spine. 2014;39:E1042.

17. Buck JS, Yoon ST. The incidence of durotomy and its clinical and economic impact in primary, short-segment lumbar fusion: an analysis of 17,232 cases. Spine. 2015;40:1444-50.

18. Puvanesarajah $\mathrm{V}$, Hassanzadeh $\mathrm{H}$. The true cost of a dural tear: medical and economic ramifications of incidental durotomy during lumbar discectomy in elderly medicare beneficiaries. Spine. 2017;42:770-6.

19. Alluri R, Kang HP, Bouz G, Wang J, Hah RJ. The true effect of a lumbar dural tear on complications and cost. Spine. 2020;45:E155.

20. Jenks PJ, Laurent M, McQuarry S, Watkins R. Clinical and economic burden of surgical site infection (SSI) and predicted financial consequences of elimination of SSI from an English hospital. J Hosp Infect. 2014;86:24-33.

21. Atkinson RA, Jones A, Ousey K, Stephenson J. Management and cost of surgical site infection in patients undergoing surgery for spinal metastasis. J Hosp Infect. 2017;95:148-53.

22. Whitmore RG, Stephen J, Stein SC, Campbell PG, Yadla S, Harrop JS, et al. Patient comorbidities and complications after spinal surgery: a societal-based cost analysis. Spine. 2012;37:1065-71.

23. D Whitehouse J, Friedman N, B Kirkland K, Richardson W, Sexton D. The impact of surgical-site infections following orthopedic surgery at a community hospital and a university hospital: adverse quality of life, excess length of stay, and extra cost. Infection Control Hosp Epidemiol. 2002;23:183-9.

24. Parker SL, Adogwa O, Witham TF, Aaronson OS, Cheng J, McGirt MJ. Post-operative infection after minimally invasive versus open transforaminal lumbar interbody fusion (TLIF): literature review and cost analysis. Minim Invasive Neurosurg. 2011;54:33-7.

25. Oderda G, Said Q, Scott Evans R, J Stoddard G, Lloyd J, Jackson $\mathrm{K}$, et al. Opioid-related adverse drug events in surgical hospitalizations: impact on costs and length of stay. Ann Pharmacother. 2007;41:400-7.

26. Hug BL, Keohane C, Seger DL, Yoon C, Bates DW. The costs of adverse drug events in community hospitals. Joint Comm J Qual Patient Saf. 2012;38:120-6.

27. Salary.com Salary Wizard-Do you know what you're worth? https://swz.salary.com/salarywizard/orthopedic-surgeon-Hourl y-Salary-Details.aspx. Accessed 1 May 2020.

28. US Inflation Calculator. US Inflation Calculator [Internet]. http://www.usinflationcalculator.com/. Accessed 1 May 2020.

29. Provider Preventable Conditions [Internet]. https://www.medic aid.gov/medicaid/financing-and-reimbursement/provider-preve ntable-conditions/index.html. Accessed 1 May 2020.

30. Toner RW, Pizzi L, Leas B, Ballas SK, Quigley A, Goldfarb NI. Costs to hospitals of acquiring and processing blood in the US. Appl Health Econ Health Policy. 2011;9:29-37.

31. Forbes JM, Anderson MD, Anderson GF, Bleecker GC, Rossi EC, Moss GS. Blood transfusion costs: a multicenter study. Transfusion. 1991;31:318-23.

32. Szpalski M, Gunzburg R, Weiskopf RB, Aebi M. Haemostasis in spine surgery [Internet]. 2001. p. 117. http://link.springer.com/ content/pdf/10.1007/b139006.pdf. Accessed 1 May 2020.

33. Lowe TG, Hashim S, Wilson LA, O'Brien MF, Smith DAB, Diekmann MJ, et al. A biomechanical study of regional endplate 
strength and cage morphology as it relates to structural interbody support. Spine (Phila Pa 1976). 2004;29:2389-94.

34. Burkus JK, Gornet MF, Dickman CA, Zdeblick TA. Anterior lumbar interbody fusion using rhBMP-2 with tapered interbody cages. Clin Spine Surg. 2002;15:337-49.

35. Surgical site infections after elective neurosurgery-ProQuest [Internet]. [cited 2020 Dec 16]. https://search.proquest.com/openv iew/7c163048a6677a9ebc15af1cfd181511/1.pdf/advanced.

36. Kim BD, Hsu WK, De Oliveira GSJ, Saha S, Kim JYS. Operative duration as an independent risk factor for postoperative complications in single-level lumbar fusion: an analysis of 4588 surgical cases. Spine. 2014;39:510-20.

37. Taylor H, H. McGregor A, Medhi-Zadeh S, Richards S, Kahn $\mathrm{N}$, Zadeh JA, et al. The impact of self-retaining retractors on the paraspinal muscles during posterior spinal surgery. Spine. 2002;27:2758-2762.

38. Datta G, Gnanalingham KK, Peterson D, Mendoza N, O'Neill K, Van Dellen J, et al. Back pain and disability after lumbar laminectomy: is there a relationship to muscle retraction? Neurosurgery. 2004;54:1413-20.

39. Freedman BA, Rhee JM, Jackson KL. Preparing the lumbar intervertebral disk space for interbody procedures: a comparison between the traditional method and a new automated method. Clin Spine Surg. 2012;25:E1.

40. Le Huec J-C, Assaker R. Comparison of powered spine shaver and conventional discectomy for TLIF: a randomized cadaver specimens study. Clin Spine Surg. 2012;25:249.

41. Lavelle WF, Ordway NR, Araghi A, Buckley RA, Fayyazi AH. An in vitro study examining a novel suction curette device for lumbar discectomy compared with standard manual discectomy. J Neurosurg Spine. 2017;26:454-8.

42. Huh H-Y, Ji C, Ryu K-S, Park C-K. Comparison of SpineJet ${ }^{\mathrm{TM}}$ $\mathrm{XL}$ and conventional instrumentation for disk space preparation in unilateral transforaminal lumbar interbody fusion. J Korean Neurosurg Soc. 2010;47:370-6.

43. Pumberger M, Hughes AP, Girardi FP, Gogia J, Kotwal SY, Thaler C, et al. Influence of surgical experience on the efficiency of discectomy in TLIF: a cadaveric testing in 40 levels. Clin Spine Surg. 2012;25:E254.

44. Singh K, Nandyala SV, Marquez-Lara A, Fineberg SJ, Oglesby M, Pelton MA, et al. A perioperative cost analysis comparing single-level minimally invasive and open transforaminal lumbar interbody fusion. Spine J. 2014;14:1694-701.

45. Kim E, Chotai S, Stonko D, Wick J, Sielatycki A, Devin CJ. A retrospective review comparing two-year patient-reported outcomes, costs, and healthcare resource utilization for TLIF vs. PLF for single-level degenerative spondylolisthesis. Eur Spine J. 2018;27:661-669.

46. Parker SL, Mendenhall SK, Shau DN, Zuckerman SL, Godil SS, Cheng JS, et al. Minimally invasive versus open transforaminal lumbar interbody fusion for degenerative spondylolisthesis: comparative effectiveness and cost-utility analysis. World Neurosurg. 2014;82:230-8.

47. Garcia RM, Khanna R, Dahdaleh NS, Cybulski G, Lam S, Smith ZA. Thirty-day readmission risk factors following single-level transforaminal lumbar interbody fusion (TLIF) for 4992 patients from the ACS-NSQIP database. Glob Spine J. 2017;7:220-6.

48. Shillingford JN, Laratta JL, Lombardi JM, Mueller JD, Cerpa M, Reddy HP, et al. Complications following single-level interbody fusion procedures: an ACS-NSQIP study. J Spine Surg. 2018;4:17-27.

49. Chan AK, Bisson EF, Bydon M, Glassman SD, Foley KT, Potts EA, et al. Laminectomy alone versus fusion for grade 1 lumbar spondylolisthesis in 426 patients from the prospective Quality Outcomes Database. J Neurosurg Spine. 2018;30:234-41.

50. Pflugmacher R, Franzini A, Horovitz S, Guyer R, Ashkenazi E. Suitability of administrative databases for durotomy incidence assessment: comparison to the incidence associated with boneremoval devices, calculated using a systemic literature review and clinical data. Int J Spine Surg. 2018;12:498-509. 